existing. The following statement does not assume convective equilibrium ; an outside radius, $R$, is assumed to exist.

Let temperature, pressure, \&c., be functions of $r$. If $m$ is the total mass bounded by the spherical surface of radius $r$,

$$
\begin{gathered}
\frac{d p}{d r}=-a \frac{m}{r^{2}} \rho \ldots \ldots \\
m=4 \pi \int_{0}^{r} r^{2} \rho \text { dr . . . . . . . . }
\end{gathered}
$$

the stuff being a perfect gas,

$$
\rho \sigma t=p . \ldots . . .
$$

If $k$ is the specific heat (in ergs) at constant volume, the total intrinsic energy of the mass is

$$
\begin{aligned}
& h=4 \pi k \int_{0}^{\mathrm{R}} r^{2} \rho t \cdot d r, \\
& h=\frac{4 \pi k}{\sigma} \int_{0}^{\mathrm{R}} p r^{2} \cdot d r
\end{aligned}
$$

The work that would have to be done in taking successive layers to an infinite distance is

$$
\mathrm{W}=+a \int_{0}^{\mathrm{R}} \frac{m}{r} 4 \pi r^{2} \cdot d r \cdot \rho=+4 \pi a \int_{0}^{\mathrm{R}} \rho m r \cdot d r
$$

Now (24) is

$$
\rho a m=-r^{2} \frac{d p}{d r}
$$

so that

$$
\mathrm{W}=-4 \pi \int_{0}^{\mathrm{R}} r^{3} \frac{d p}{d r} d r=-4 \pi \int_{p_{0}}^{0} r^{3} d p \ldots
$$

Now in $(27)$

$$
\int_{0}^{\mathrm{R}} p r^{2} \cdot d r=\left[\frac{1}{3} p r^{3}\right]_{0}^{\mathrm{R}}-\int_{p_{0}}^{0} \frac{r^{3}}{3} d p
$$

The bracket term is o, as $r$ is o at the centre, and $p=0$ at the surface. Hence 27 is

$$
h=-\frac{4 \pi k}{\sigma} \int_{p_{0}}^{0} \frac{r^{3}}{3} d p
$$

Dividing by (29) we have

$$
\frac{h}{\mathrm{~W}}=\frac{k}{3^{\sigma}}
$$

Now in gases, if $\mathrm{K}$ is specific heat at constant pressure $\sigma=\mathrm{K}-k$ so that

If

$$
\begin{gathered}
\frac{h}{\mathrm{~W}}=\frac{k}{3(\mathrm{~K}-k)}=\frac{\mathrm{I}}{3(\gamma-\mathrm{I})} \\
\gamma=\mathrm{I} \frac{1}{3}, h=\mathrm{W} \\
\gamma=\mathrm{I} \cdot 4, h=\cdot 833 \mathrm{~W}
\end{gathered}
$$

If

Here are very definite astonishing statements !

I must confess that I do not understand how if $\gamma=I \frac{1}{3}$ we can have $h=\mathrm{W}$. It seems to mean that if a mass of this kind of gas gravitates by itself from an infinite distance it retains all its energy. But such gas must surely be imagined to be radiating heat, as it is not at zero temperature. Where can it get such heat ? I come to the conclusion that there must be atomic energy available somehow in it, even when we imagine the molecules at an infinite distance from one another, or else there is no such gas possible. I say that no substance for which $\gamma=\mathrm{I} \frac{1}{3}$ can behave as a perfect gas.

You will notice that we do not need to imagine our stuff in a state of infinite diffusion. If a gaseous star changes its size or the arrangement of its stuff, the gravitational work done is exactly equal to the additional intrinsic heat energy in the star if $\gamma$ is $I \frac{1}{3}$. The paradox is greater if we think of coloured diatomic gases such as chlorine, NO. I 550 , VOL. 60] which have values of $\gamma$ less than $I \frac{1}{3}$. We must either assume that there is more energy available than mere gravitational energy, or else that such substances cannot really behave as perfect gases. [It is to be remembered that by a perfect gas I do not merely mean that $p / t \rho$ is constant, but that $k$, the specific heat at constant volume is constant, a statement which does not follow from the first.] It is some time since I have come across a statement which looks better worth study than this one.

WILLIAM HENRY FLOWER, K.C.B., F.R.C.S., LL.D., D.C.L., SC.D., F.R.S., F.Z.S., F.L.S.

THE distinguished naturalist whose death has recently occurred was the second son of the late Mr. Edward Fordham Flower, the founder of the well-known brewery at Stratford-on-Avon, and dear to all lovers of animals on account of his crusade against the bearingrein. Sir William Flower was born in November $183 \mathrm{I}$. $\mathrm{He}$ was educated at private schools and at University Collese, London, where he took Sharpey's gold medal in Physiology, and Grant's silver medal in Zoology. He became M.B. of the University of London in $185 \mathrm{I}$, and joined the Medica! Department of the Army in 1854 , serving in the Crimea, where his health broke down. On his return to England he became Demonstrator of Anatomy at the Middlesex Hospital, and Curator of the Museum, intending to practise as a surgeon. Here he published his first work, "Diagrams of the Nerves of the Human Body" and also wrote in Holmes" "System of Surgery." on "Injuries of the Upper Extremities."

In 1861 , at the age of thirty, he was appointed to succeed Queckett as Curator of the Hunterian Museum at the College of Surgeons, and later became Hunterian Professor. Thenceforward he abandoned professional work for purely scientific pursuits. Twenty years later, when he received the Royal medal of the Royal Society, the President stated with justice that "it is very largeiy due to his incessant and well-directed labours that the museum of the Royal College of Surgeons at present contains the most complete, the best ordered, and the most accessible collection of materials for the study of vertebrate structures extant."

'Two years later (in 1884 ), on the resignation of Sir Richard Owen, Prof. Flower was appointed Director of the new Natural History Museum in the Cromwell Road, where he was incessantly occupied with the arrangement and development of the collections until failing health necessitated his resignation, which took effect in October 1898 . Unhappily he did not long enjoy the rest and leisure which he had so well earned by a life of unusual industry and devotion to public work.

His services in the cause of knowledge were recognised by many honorary degrees from Universities, and by his election as a Correspondent of the Institute of France. He was made C.B. in 1887 , and K.C.B. in 1892 , and was President in 1889 of the British Association for the Advancement of Science.

The mere enumeration of the incidents in a man's life does not tell very much about the nature and value of his work. Sir William Flower's chief work was in two directions: firstly, as a director and original artist in museum management; secondly, as an investigator and discoverer in the comparative anatomy of the Mammalia. Besides these two chief lines of work, there were others to which he gave time and care. He was not unheedful of the popular demand for instruction and guidance by lectures. He frequently appeared at the Royal Institution and the London Institution, and always had a weighty and well-considered discourse to deliver. The most original and, from a social point of view, the most important of these was one on "Fashion in Deformity," in which he gave very strong support to those who dis- 
approve of tight-lacing, high-heeled shoes, and other monstrosities of clothing. Another way in which Sir William Flower gave voluntarily a large amount of valuable work to the community was as President first of the Anthropological Institute, and then of the Zoological Society-a post which he held until his death. Such services in our scientific societies are given without any remuneration, and they can only be repaid by the grateful acknowledgment of those interested in the progress of the branches of science thus benefited.

To revert to the two chief lines of Sir William Flower's life-work. He first became generally known in the scientific world by joining the band of young anatomists who supported Huxley in his rejection of the statements made by $O$ wen as to the differences between the brain of man and of apes. Like the other members of that group-Turner, Humphrey, and Rolleston -Flower published an important contribution to the controversy. This memoir, entitled "Observations on the Posterior Lobes of the Quadrumana," was printed in the Philosophical Transactions in 1862 ; and about the same time Flower wrote also on "the brain of the Siamang" in the Natural History Review. His most numerous contributions to anatomical science relate to the Cetacea, which was his favourite group. After the deaths of P. J. Van Beneden and Gervais, he was only rivalled in his knowledge of whales by Sir William Turner, of Edinburgh. It was a special satisfaction to Flower to have been able to complete the admirable exhibition of whales at the Natural History Museum before his retirement-an exhibition which is not only unequalled, but is not even attempted in any other museum in Europe or America. Next to the Cetacea, the subject on which Flower worked and wrote most was physical anthropology. His catalogue of the anthropological series in the museum of the Royal College of Surgeons and its introductory chapter have served as classics to English anthropologists, and are the result of an immense amount of patient research. Separate papers by him on the osteology of the Andaman Islanders and of the Fijians are of great value on account of the large amount of material dealt with, and the caution and judgment shown in drawing conclusions. Caution and reticence in generalisation certainly distinguish all Flower's scientific writings. Whilst he was on this account necessarily not known as the author of stirring hypotheses, his statement of fact gained in weight by his reputation for judgment and accuracy. The most important discovery in anatomical science which we owe to him is that of the existence of but one successional molar in the marsupial Mammals. This sharply defined and important fact was only one, but the most striking, of the results of a long, conscientious and painstaking study of the dentition of the Mammalia. The next most striking discovery which we owe to Flower seems to me to be the complete and convincing demonstration that the extinct marsupial called Thylacoleo carnifex by Owen was not a carnivor, but a gnawing herbivorous creature like the marsupial rats and the wombat - a demonstration which has been brought home to the eye even of the unlearned by the complete restoration of the skull of Thylacoleo in the Natural History Museum prepared by Dr. Henry Woodward. Another thoroughly original and elaborate piece of work which should, I think, be especially remembered in attempting to survey Flower's anaton;ical labours, is the attempt to bring order and system into the study of the forms presented by the lobes of the liver in the Mammalia, an effort which has not, perhaps, as yet borne all the fruit of which it is capable.

In such a brief notice as the present a complete bibliography of Sir William Flower's contributions to anatomical science cannot be given, but a fair notion of his great activity in research can be obtained from a selected list. Relating to the Cetacea, I would cite the following papers from the Proceedings of the Zoological Society:On a lesser Fin-whale (Balænoptera rostrata) stranded on the Norfolk Coast (I864); the skeletons of Whales in the Principal Museums of Holland and Belgium (1864); on a new species of Grampus from Tasmania (1864); on Physalus Sibbaldii (1865); on Pseudorca meridionalis, I 865 ; on a Fin-whale stranded in Pevensey Bay (1865) the probable identity of Balænoptera Carolinæ and Physalus Sibbaldii ( 1868 ); on the Whales of the genus Hyperoodon (1882); on the Characters and Divisions of the Family Delphinida (1883); then in the Transactions of the same Society, the fine illustrated papers on the skeleton of Inia Geoffrensis (1869); on the osteology of the Cachalot $(1869)$; on the skeleton of a Chinese White Dolphin (1872); on Risso's Dolphin (1873); on recent Ziphioid Whales (1878); on two species of British Dolphins ( 1880 ) ; and the translation of and introduction to Eschricht's treatise published by the Ray Society. Also in the Proceedings of the Royal Institution, Whales Past and Present, and their probable origin ( $188_{3}$ ).

Relating to physical anthropology, Sir William Flower's most important works are the following :-The Catalogue of Specimens in the Museum of the Royal College of Surgeons, 1879 and 1884 (already referred to above), in the Journal of the Anthropological Institute; the osteology of the natives of the Andaman Islands (1879); the osteology of the Fijians (I880); the osteology of the Mallicolese (188I); the aims and prospects of the Study of Anthropology (1884); the Classification of the Varieties of the Human Species (1885); on the size of Teeth as a character of Race (1886); in the Proceedings of the Royal Institution (a Friday evening discourse) on the Native Races of the Pacific (1878); and in the Manchester Science Lectures, a discourse on the aborigines of Tasmania (I 866).

Ranging over other groups of Mammals, I would cite the following papers:-On a newly-discovered extinct Mammal (Homalodontotherium) from Patagonia (Phil. Trans., 1873); Description of the skull of a species of Halitherium from the Red Crag of Suffolk (Quart. Journ. Geol. Soc., 1874); on the remains of Hyænarctos in the Red Crag of Suffolk (ibid., I877). From the Proceedings of the Zoological Society: papers on the anatomy of Galago (1862); of Pithecia monachus (1862); on the brain of the Echidna (1864), on the brain of the Red Howling Monkey (1864); on the anatomy of Hyomoschus (1867); on the development of the teeth in the Armadilloes (1868); on the characters of the base of the cranium and the classification of the order Carnivora (1869); on the anatomy of Proteles cristatus (1869); and on that of Aelurus fulgens (1870); and of the two-spotted Paradoxure (1872) ; and of the Musk Deer (1875); on the cranial and dental characters of the existing species of Rhinoceros ( 1876 ); and on the mutual affinities of the animals composing the order Edentata (1882).

Of a more general character are his articles in the "Encyclopædia Britannica":-On the anatomy and zoology of the Horse, Kangaroo, Lemur, Lion, Mammalia, Mastodon, Megatherium, Otter, Platypus, Rhinoceros, Seal, Swine, Tapir, \&c. These have formed the basis of a very useful volume on the Mammalia published by Messrs. Black, whilst the compact little volume on the osteology of the Mammalia by Sir William Flower is known to all University students. The last volume which came from his pen is one of the best and most interesting, namely that called "The Horse: a study in natural history," published in I 892 .

Having thus indicated (and only "indicated" by no means "enumerated" or "fully set down") the labours of Sir William Flower in anatomical research, I pass to a brief consideration of his work as a museum curator, which probably took up more of his time and energy than he was able to give to original investigations. This

NO. I 550 , VOL. 6o] 
is most certainly true of the second portion of his scientific life, which dates from his appointment in 1884 to the directorship of the Natural History Museum, and was preceded by twenty years of work as Hunterian Curator. There can be no doubt in the mind of any man who is acquainted with the present condition of the public galleries of the great nuseums of natural history in Europe, and with the condition which characterised those of similar institutions in Great Britain previously to the year 1864 , that a very great and important change for the better was effected by Flower, first of all at the College of Surgeons, and later in accordance with a further development of his ideas, at the Natural History Museum (British Museum, Natural History). The arrangement and exhibition of specimens designed and carried out by Flower in both instances was so definite an improvement on previous methods, that he deserves to be considered as an originator and inventor in museumwork. His methods have not only met with general approval, and their application with admiration, but they have been largely adopted and copied by other curators and directors of public museums both at home and abroad. In his address as President of the British Association, and also in an address to the Museums Association, Sir William Flower has explained in some detail the theory which he held with regard to the proper selection and arrangement of objects in a public museum. The general conception which Sir William Flower had formed was accepted and developed in detail by that gifted and genial museum-director, Brown Goode, of Washington, U.S.

It is simple enough and convincing. But the work of the museum curator consists not merely in framing theories of museum organisation and arrangement: the more important part of his work is the putting of such theories into practice. To do this, energy and patience in the surmounting of obstacles are necessary, and perhaps as much as or more than any other quality- the artistic sense. Sir William Flower possessed this last quality in a remarkable degree. No pains were spared by him in selecting the proper colour for the background or supports of the specimens exhibited in a case, or in effectively spacing and balancing the objects brought together in one field of view. He took the greatest pains to make the museum under his care a delight to the eye, so that the visitor should be charmed by the harmony and fitness of the groups presented to his notice, and thus the more easily led to an appreciation of the scientific lesson which each object has to tell. There are public galleries in some of the natural history museums of Europe where the specimens are so crowded and illplaced, where the lighting is so badly designed and the prevailing colour of case and wall so depressing, that the main purpose of the exhibition is defeated by the fact that the visitor becomes seriously attacked by headache before he has been able to ascertain what there is for him to look at, or why he should look at anything at all, in the appalling accumulation spread before him. It was Sir William Flower's merit to have introduced a better way, and so far as opportunity and the brief fourteen years of his directorship allowed him to do so, he put that better way into practice at the national museum of natural history. The first great principle upon which Sir William Flower insisted was that the possessions of a great museum of natural history must be divided into two distinct parts - to be separately dealt with in almost all respects-viz. the public or show-collection, and the special or study-collection, not exhibited to the general public, but readily accessible to all investigators and specially qualified persons. The latter collection, he insisted, should have at least as much space devoted to it as the former. In this way the public galleries would (he showed) be cleared of the excess of specimens which, nevertheless, the museum must carefully preserve for the use of specialists. Then, further, Flower held that every specimen placed in the public or show-collection should be there in order to demonstrate to the visitor some definite fact or facts, and so should be most fully visible, isolated rather than obscured by neighbouring specimens, and ticketed with an easily-read label stating clearly and simply the reason why it is worth looking at - that is to say, what are its points of interest. $\mathrm{He}$ would thus have reduced very much in number the specimens commonly exhibited in natural history museums, and have increased the interest and beauty of each specimen selected for the public eye. Another principle which he often insisted upon-but was not able to put fully into practice owing to long-standing arrangements in the museum over which he presided--was that in the public galleries the skeletons of animals should not be placed in one room and the stuffed skins in another, and the soft parts in a third, and the fossilised remains of extinct allied animals in a fourth more or less remote chamber; but that the visitor should see, side by side, the stuffed or otherwise preserved animal (mammal, bird, reptile, fish, mollusc, insect, worm or polyp) and its skeleton and important parts of its internal structure and the remains of its extinct allies. Thus, there would be, not three or four separate zoological collections for the amazed visitor to traverse and bring into correlation by mental effort, but one only, in which the story of each animal is told as completely as possible in one connected exhibit. It is simply a fact that the "art of arranging museums for the public" is in its infancy, and that it was mainly, if not entirely (so far as natural history is concerned) founded by William Henry Flower. Like other originators, he did not live to see the principles which he advocated fully acted upon, nor did he expect to do so. He knew that time is a necessary element in such developments. But he has left an enduring mark on what we may call "museum policy." His teaching and performance are producing, and will continue to produce, progress towards the realisation of his ideals.

Sir William Flower did not train or produce any pupils. He did his own work with his own hands, and I have the best reason to know that he was so deeply shocked and distressed by the inaccuracy which unfortunately crept into some of the work of his distinguished predecessor Owen, through the employment of dissectors and draftsmen whose work he did not sufficiently supervise, that he himself determined to be exceptionally careful and accurate in his own records and notes. In later years, he had the assistance of young anatomists in making the beautiful preparations which are placed in the central hall of the museum. One of his assistants, Mr. Wray, whilst preparing, under Sir William Flower's direction, specimens for the museum to exhibit the disposition of the feathers in the wings of birds, discovered the strange and puzzling fact that the fifth cubital quill is apparently absent-that is to say, there is a gap where it should be-in whole orders and families of birds, whilst it is present in other orders and families. The discovery of the wide-spread occurrence of aquintocubitalism--as it has been called-was thus made in Sir William Flower's work-room, and in connection with his scheme of museum exhibition.

It is well to place on record that Sir William Flower was a convinced Darwinian. At the meeting of the Church Congress at Reading in October 1883, he had the courage to open a discussion on "Recent Advances in Natural Science in their relation to the Christian Faith," his expressed object being to mitigate the prejudices of many of the strongest opponents of the doctrine of evolution amongst the clergy.

Whilst discharging in so many different ways important public duties, and holding up amongst scientific men a high standard of accurate work and unremitting devotion

NO. I 550 , VOL. 60] 
to the progress of zoological knowledge, Sir William Flower found time to extend very largely among the educated classes an interest in the aims and results of zoology by the willing courtesy with which he received visitors at the Museum in Cromwell Road, and explained its contents. His interest in his work there was so sincere that no zoologist ever asked in vain for his help and advice in museum matters. He was so earnest in carrying out his new devices for the effective exhibition to the public of zoological specimens that even on his busiest days he would find a few minutes to show his latest improvements to one who sympathised with his aims and believed in his methods.

Personally, I owe very much to him in this way. I am glad also to be able to acknowledge here the help which he gave to me by supporting in a valuable letter, which was printed and circulated at the time, the re-arrangement of the zoological and anatomical collections in the University Museum at Oxford, which I had proposed and was enabled subsequently to carry out-largely in consequence of the weighty opinion which Sir William Flower gave in its favour.

E. RAY LANKESTER.

\section{THE DUTIES OF PROVINCIAL PROFESSORS}

D URING the past twenty years numerous centres of university education have grown up all over our country, and much public money has been spent in their endowment. Some of these colleges have already risen to the rank of universities with the power of conferring degrees; others are eagerly pressing forward in the same direction in the hope of competing with their more fortunate rivals. If this multiplication of universities is not to result in lowering the prestige of British university degrees, but to enable us to compete in the matter of scientific education with foreign countries, it is of the utmost importance that the professorial staffs of our younger university colleges should be placed under the most favourable positions for establishing the reputations both of themselves and of their colleges in the matter of higher study and research. The time appears to have come when we must face much more boldly than hitherto the question whether the conditions attaching to provincial professorships and lectureships, even in some of our most successful university colleges, are conducive or inimical to progress in such respects.

In calling attention to the serious and, to our mind, unnecessary disadvantages under which provincial professors are often placed at the hands of their Councils or Governing Boards, our remarks must be understood to be based on a considerable number of experiences of which we have gathered details during some years.

A foreign professor may only lecture five hours a week, and devote the rest of his time to research, and yet be regarded as discharging his duties fully and efficiently. Under such a system German professors have filled their class-rooms with the best students drawn from all parts of the world, German degrees are rising in public estimation year by year, English students are going out of their own country for the higher training they cannot obtain at home, and we are mainly indebted to Germany for our standard literature on every branch of science.

In America university development is more recent, but the majority of universities are lavishly staffed with professors and assistant lecturers, who thus have ample time for research ; and the system has been introduced of giving these teachers one free year in seven, in order that they may be able the better to keep themselves abreast with the most recent developments of their science. Under such conditions, America is rapidly pressing forward in scientific research, and American text-books are slowly and surely finding their way into English classrooms.

NO. I 550 , VOL. 60]
As instances of what one university can do in pro moting research, even in a single department of science, we need only call attention to the Communications from the Physical Laboratory of the University of Leiden, published periodically in English, or the Physical Revieze, brought out under the auspices of Cornell University.

Our modern centres of university education are largely bound down to the policy of attracting the greatest number of students, not by the reputations of their professors, but by the attractions they offer in small bursaries and in facilities for cheaply acquiring pass degrees. Under this system a professor may give fifteen lectures a week or more, and spend most of the rest of the day in the laboratory; but there is no limit to the extraneous work required of him by his Council or Governing Board, beyond that research work forms no part whatever of his obligations. We do not deny that good work is done in this country by many provincial professors, but it is often done under extreme difficulties, and many others are debarred from taking that place in the scientific world for which their abilities qualify them.

With regard to the lectures themselves, these are almost exclusively limited by the syllabus of examinations for pass degrees. Matriculation preparation forms a heavy item in the work of most departments, and one to which great importance is commonly attached. It is the duty of the professor not so much to push forward his best students as to adapt his lectures to the requirements of the average student, and to bring as many as possible up to pass standard. $\mathrm{He}$ is held responsible for the attendance and diligence of his students in class, and is bound to make records of these matters ; while out of class he and his colleagues are jointly responsible for general discipline, even extending to the rules of athletic clubs. $\mathrm{He}$ is required to set and correct exercises and examination papers at frequent intervals. If students have not followed his lectures properly he is expected, often at short notice, to provide tutorial instruction without limit to those whose chances of passing are in danger-an arrangement, by the way, hardly calculated to ensure students giving their best attention to professorial lectures.

We do not imagine that any professor, if left to himself, would be wanting in willingness to give a large amount of his private time to helping students over difficulties, and making his lectures convey the greatest amount of instruction with the least amount of work. But if a professor makes a conscientious stand against cramming, or puts any personality into his professorial work, he runs the serious risk of losing at a few weeks' notice the post he has held for years, at the hands of a Governing Board who misinterpret his action because they have no knowledge of the conditions attaching to a sound teaching of his subject. In such cases students, who are more concerned about getting a degree than about the thoroughness of their training, may be called on to give evidence against their professor. We have knowledge of several instances in which colleges have on insufficient grounds lost the services of men who have been doing good work for them, whose teaching has been acknowledged to be successful, and who, under less disadvantageous conditions, would have done them credit by their scientific work.

The practical result of this system is that our modern university centres, whether chartered or not, are devoting their endowments to competing for cheap pass degrees with one another, and with private institutions and tutors who prepare for London University and similar examinations. The students spend the whole day in class-rooms and in laboratories, and when they have done the exercise work required by their teachers, the day is gone and they are too tired to think over what they have learnt. Their professors are thus required to do the thinking for them. 